\title{
Effects of Personality Traits and Team Context on Individual Innovative Behavior (Exploitation and Exploration)
}

\author{
Mihye Park ${ }^{1}$ and Seongsu Kim ${ }^{2, *(1)}$ \\ 1 Institute of Industrial Relations, Graduate School of Business, Seoul National University, Seoul 08826, Korea; \\ aroma428@snu.ac.kr \\ 2 Graduate School of Business, Seoul National University, Seoul 08826, Korea \\ * Correspondence: sk2@snu.ac.kr
}

check for updates

Citation: Park, M.; Kim, S. Effects of Personality Traits and Team Context on Individual Innovative Behavior (Exploitation and Exploration). Sustainability 2022, 14, 306. https:// doi.org/10.3390/su14010306

Academic Editor: María del Mar Molero Jurado

Received: 17 October 2021

Accepted: 23 December 2021

Published: 28 December 2021

Publisher's Note: MDPI stays neutral with regard to jurisdictional claims in published maps and institutional affiliations.

Copyright: (c) 2021 by the authors. Licensee MDPI, Basel, Switzerland. This article is an open access article distributed under the terms and conditions of the Creative Commons Attribution (CC BY) license (https:// creativecommons.org/licenses/by/ $4.0 /)$.

\begin{abstract}
This study analyzed how personality traits, team context, and the interaction between the two affect individual exploitation and exploration. Analyses of data from two Korean firms revealed that personality traits have an effect on individual exploitation and exploration activities. Specifically, the authors found that those with high-level openness to experiences engaged in high-level exploration activities. By contrast, those with high-level conscientiousness pursued high-level exploitation activities. For individual exploitation and exploration activities, the team context perceived by individuals was also important. Furthermore, this study confirmed the effect of the interaction between personality traits and team context on individual exploitation and exploration activities.
\end{abstract}

Keywords: ambidexterity; big five personality traits; exploitation; exploration; individual exploitation; individual exploration

\section{Introduction}

Ambidexterity is beneficial to the sustainable performance of an organization [1]. In a dynamic environment, successful businesses are ambidextrous, meaning they are aligned and efficient in managing today's business demands, while also adapting to changes in the environment to survive tomorrow [1,2]. Demands placed on an organization, in its work environment, are constantly in conflict to some degree (for example, current versus future initiatives and differentiation versus low-cost production); hence, there are always conflicts or trade-offs [1]. Although these trade-offs will never be completely eradicated, the most successful businesses are able to reconcile them to a great extent, improving their long-term competitiveness in the process [1].

Recent studies on ambidexterity focus on its behavioral model, which stresses that a firm's ambidexterity comes from its human resource system [3]. Building on this view, the perspective of Gibson and Birkinshaw [1] on ambidexterity has been added, and studies have begun to examine how human resource systems can help develop a behavioral context that encourages employees to engage in exploitation and exploration [4].

In this regard, while various contextual ambidexterity studies have been performed recently, the following important points have been overlooked. First, although research has recognized the importance of individual employees' behaviors and human resources in ambidexterity, it has mostly paid attention to contexts such as the systems or schemes that support individuals (e.g., [1]). A representative example is the study of Gibson and Birkinshaw (2004), which emphasized contextual ambidexterity. Contextual ambidexterity is about establishing a set of processes or systems that allow people to make their own decisions about how to balance competing demands for exploitation and exploration [1]. Hence, few studies have examined what individual characteristics contribute to ambidexterity. Even studies on the effect of individual characteristics on ambidexterity have not considered personality traits. Existing studies have looked at the relationship between, for example, the ability of a decision-maker [5], the direction to get out of the existing state [6], 
intelligence [7], and ambidexterity. Although there are studies on the relationship between personality and creativity, it is difficult to find a direct connection between personality and ambidexterity. Given that personality traits lead to behaviors, they serve as the basis to explain individuals' various behaviors. Personality is a consistent trait that predicts behavior, and personality influences an individual's behavior and performance [8]. Personality is also related to learning and cognitive aspects [9], so it is possible to link personality with exploitation and exploration. Gibson \& Birkinshaw's studies emphasizing contextual ambidexterity, also suggesting the importance of the individual behind the scenes. It is because although ambidexterity is a general property of a business unit, it is manifested in the unique activities of individuals within the organization. Individuals are frequently faced with decisions on how to spend their time in their day-to-day employment [1]. With the view that individual traits are as important as the contextual characteristics (e.g., [1]), this research, hence, analyzes the effect of personality traits on the exploitation and exploration behaviors of individuals.

Second, although many previous studies on ambidexterity have been conducted at the organizational level, and some have been performed recently at the sublevel, studies at the sublevel are still lacking [10]. Specifically, the understanding of how the members of an organization deal with conflicting demands; additionally, integrating exploitation and exploration activities is limited [11]. Many studies argue that exploitation and exploration activities should be integrated by not only the top group but also the bottom group, and performance can be improved when low-ranking managers behave ambidextrously [1,4] Considering that the contextual perspective on ambidexterity examines how frontline managers make routine choices in the organizational context, ambidexterity can be regarded as a multi-level construct. Studies at the sublevel allow us to further understand the complexity of ambidexterity and reveal the organizational mechanisms, institutions, and actors that underpin it $[10,12]$.

Third, expanding on contextual ambidexterity studies, the current research examines the interaction between team context and personality traits for individual exploitation and exploration. Mom et al. [4] argued that the effectiveness of ambidextrous managers depends on the characteristics of the work environment that they are in; they also pointed out the lack of understanding of what conditions make ambidextrous managers most effective.

Given that studies on the preceding variables, which improve ambidexterity, are seriously lacking, this research examines which personality traits interact with which contextual situations. That is, the authors analyzed what personality traits, with different team context features, lead to different levels of exploitation and exploration.

\section{Theory and Hypotheses}

\subsection{Individual Exploitation and Exploration}

On the basis of previous studies [13-15], the current research defines individual exploitation as "improving existing knowledge and ideas and extracting value by relying on previous knowledge". Exploitation produces outcomes in the processes related to behaviors, cognition, and learning. For instance, exploitation uses existing knowledge to improve an existing type of product and mainly refers to a small change that reflects a minor modification, not a huge change. Exploitation is performed in relation to not only products but ideas, knowledge, methods, processes, technologies, and competencies, including cost reduction or routine use.

Considering previous studies [13-15] together, the current research defines individual exploration as "looking for a new idea on the basis of new knowledge, which has not been used". Exploration produces outcomes through behavioral, cognitive, and learning processes. While exploitation represents small and gradual changes, exploration refers to activities that result in new products, ideas, knowledge, institutions, competencies, and processes that are quite different from existing ones. It also includes taking risks and finding new routines. 
Exploration can be regarded as each individual's decision making to achieve strong innovation and high-level learning [15]. Hence, the key is how an organization sets up an institution or a context to encourage individuals to engage in their job at a high level, such as proposing original ideas and how they elicit such behaviors. Given that exploration is more difficult to achieve than exploitation, an organization needs extra energy to improve the level of exploration.

Hence, this study's underlying assumption is that an individual engages in exploitation and exploration activities [1,16]. Given that the level of engagement in the two activities differs, depending on the individual's personality traits, and is important in this regard; an individual can also pursue exploitation or exploration activities better when an appropriate context is provided that fits his or her personality traits.

\subsection{Personality Traits, Exploitation, and Exploration}

Funder [17] defined personality traits as "characteristic patterns of individuals' thoughts, emotions, and behaviors along with the psychological mechanism". Personality traits are consistent characteristics that can predict behaviors [8]. Personality traits also affect individuals' behaviors and performance. The reason why personality traits are associated with individual exploitation and exploration is that personality traits lead to behaviors and are related to learning and cognition. That is, considering that exploitation and exploration also have behavioral, cognitive, and learning aspects, personality traits are connected to them.

Openness to experience and conscientiousness are associated with creative behaviors in the workplace [18]. Accordingly, the present study sets hypotheses on openness to experience and conscientiousness. Personality traits affect individuals' innovative behaviors, work effectiveness (in part), and level of innovative behaviors; that is, exploitation and exploration activities may be closely related to people with high-level openness to experiences or conscientiousness. Furthermore, team context may affect the level of individual exploitation and exploration activities. The relationship among personality traits, exploitation, and exploration may vary, depending on team characteristics. The roles of context have been discussed for ambidexterity; thus, in this study, team context was chosen for influencing ambidexterity. Among them, it is important to focus on the team context that interacts with personality traits. From Gibson and Birkinshaw, who discussed important contextual elements in an ambidextrous organization, contextual elements are predicted to have positive effects on exploitation and exploration [1]. This study selects two contextual variables that may improve individual exploitation and exploration from all available sources, including the situation (which is important in the theory of personality traits), contextual features (which are important in the theory of ambidexterity), context (which is important in studies on creativity and innovation), and other information from interviews with firms. Specifically, in this study, we understand context as suggested by Gibson and Birkinshaw [1]. Team context comprises of performance management context, including the concepts of training and stretch (which can be represented by task characteristics) and social context, including the concepts of support and trust (which can be represented by social characteristics). Knowledge sharing is regarded as an important variable in the performance management context. Meanwhile, support from the team leader and members are considered important variables in the social context. Figure 1 illustrates the study model described above.

\subsubsection{Openness to Experiences and Exploration}

In terms of individual exploitation and exploration, openness to experiences is expected to have a positive relationship mainly with exploration activities, attributable to the below characteristics of openness to experiences. Openness to experiences means a tendency to be curious, like new experiences, and have an open attitude toward various experiences and values [19]. People with high-level openness to experiences tend to be intellectually curious, seek new experiences, and explore new ideas [20]. They can be described 
as "creative", "innovative", "imaginative", "thoughtful", and "unconventional" [20]. Furthermore, people with high-level openness to experiences are characterized by originality and creativity [21]. Those with low-level openness to experiences tend to be traditional, have a narrow range of interest, and not be analytical [20]. Openness to experiences has a positive relationship with intelligence, related to creativity, similar to diverse thinking [20]. Those open to experiences have a high-level "desire for diversity" [22]. Therefore, people with high-level openness to experiences are attracted to new job demands and tend to seek different roles, apart from the job activities that they have faced before [21].

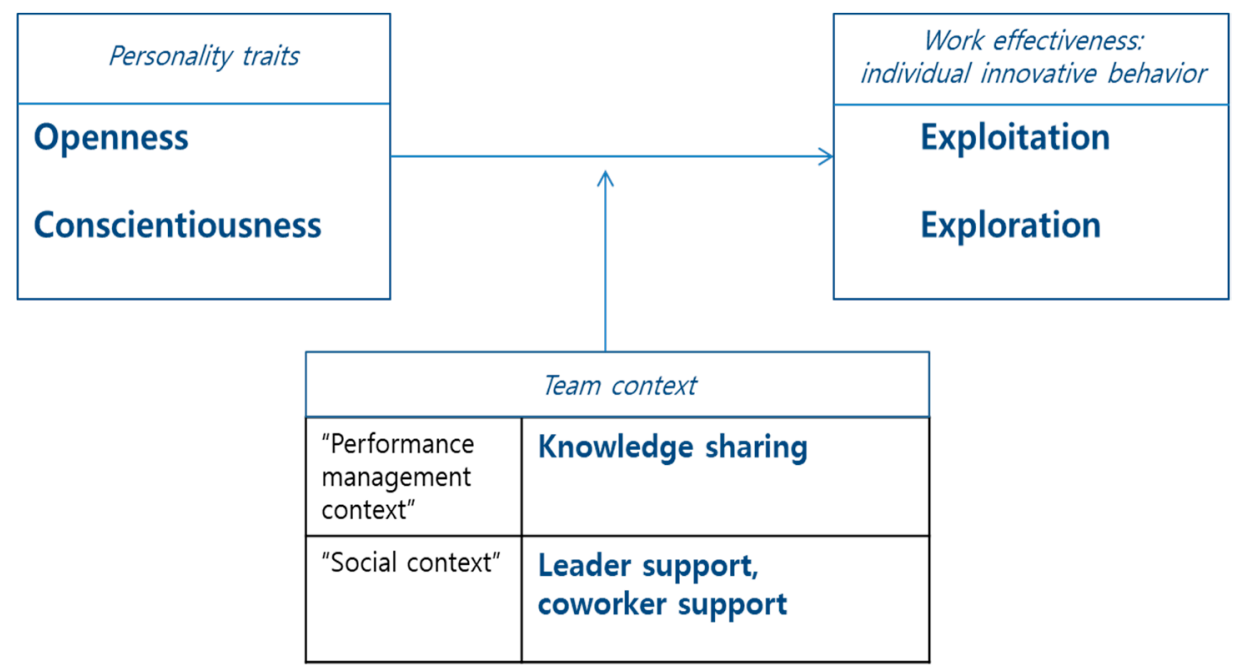

Figure 1. Research model.

That is, those with high-level openness to experiences can be considered to have a tendency to work in a new way that presents new ideas and solutions. Furthermore, they have: different emotions, thoughts, perspectives, and ideas; possess a high-level desire for diversity; and are open to various experiences and values [7,23]. Given that exploration is about looking for new ideas, on the basis of new knowledge, that have not been used before, those with high-level openness to experiences likely do more exploration activities than those with low-level openness to experiences.

Hypothesis 1 (H1). Openness to experiences is positively related to exploration.

\subsubsection{Conscientiousness and Exploitation}

Conscientiousness refers to a strong achievement-oriented tendency to control oneself well and have strong responsibility [19]. People with high-level conscientiousness tend to be responsible, careful, patient, organized, attentive, planned, hard-working, and achievementoriented [24].

Conscientiousness refers to goal-oriented learning behaviors [25]. Existing experiences, which can be exploited to reach a set goal, are required to follow the set goal [25]. Tasks that require exploitation are relevant to activities related to existing knowledge and competencies and include improving a given routine, applying a standard, or focusing on improving trust on the basis of existing knowledge $[25,26]$. Considering that people or managers with high-level conscientiousness are highly likely to experience such types of tasks and meet standards in reaching a set goal, they engage in additional exploitation tasks [25]. Hence, conscientiousness is more associated with exploitation than exploration.

In addition to the above characteristics of conscientiousness, while people with highlevel conscientiousness tend to follow rules and conform to customs [19] and perform extraordinarily at a given existing task, as they work hard to reach a set goal [18]; conscientiousness itself does not really entail changing the status quo and finding a new way. 
Conscientiousness is more associated with focused thinking than diverse thinking and, therefore, has more to do with exploitation than exploration [7].

With regard to the nature of the relationship between conscientiousness and exploration, the level of exploration activities performed by conscientious people may vary, depending on how much exploration a team demands and what characteristics their team has. Previous studies did not consistently identify the relationship between conscientiousness and creativity; the reason is because such a relationship is considered complex, as the creativity or innovation level required by a task or industry differs [27]. Given that theoretically defining the relationship of conscientiousness with exploration is difficult, and conscientious people are expected to conduct more exploitation activities than exploration activities, the authors propose the following hypothesis only for the relationship between conscientiousness and exploitation.

\section{Hypothesis 2 (H2). Conscientiousness is positively related to exploitation.}

\subsection{Team Context, Personality Traits, and Exploitation and Exploration}

This section examines the effect of team context on individual exploitation and exploration activities, including the effect of interaction between personality traits and situation of exploitation and exploration. The situation, in this sense, is based on the context suggested by Gibson and Birkinshaw [1], which comprises the performance management context to reinforce "discipline" and "stretch", as well as the social context to strengthen "trust" and "support". These elements in the organizational context improve contextual ambidexterity. In this study, knowledge sharing is used as the performance management context and support from the team leader and members are regarded as the social context.

\subsubsection{Interaction between Personality Traits and the Situation}

This research is mainly about the effects of openness to experiences on exploration and conscientiousness on exploitation. It examines contextual elements' moderating effect on them. Given that these contextual elements are, to a large extent, predicated on Gibson and Birkinshaw [1], who discussed important contextual elements in an ambidextrous organization, they are predicted to have positive effects on exploitation and exploration.

Therefore, the contextual elements, suggested in this study, are regarded as strong situations that affect exploitation and exploration. In the relationship with exploitation, these contextual elements have an effect on the relationship between personality traits and exploitation, based on the situation strength. In the relationship with exploration, they contribute to exploration, but the logic of situation strength does not work; instead, they play a role in activating or enabling the traits.

In the relationship between personality traits and exploitation, as per the logic of situation strength, which is generally observed in the relationship between personality traits and performance, contextual elements work as a strong situation and show a negative moderating effect. By contrast, in the relationship between personality traits and exploration, the contextual elements enable exploration and show a positive moderating effect, even though the contextual elements constitute a strong situation. The reason is not only do the contextual elements activate traits in exploration, but they also enable exploration, since exploration is more difficult to achieve than general performance. Additional efforts are required for exploration and enabling exploration is difficult; hence, high-level motivation and a context that elicits such motivation are necessary, which we call "enabling situation". In the relationship between personality traits and exploration, a situation that enables exploration may reinforce the relationship between personality traits and exploration. This logic has not been discussed in previous studies on the relationship between personality traits and performance and is totally different from traditional perspectives. The reason is that previous logics on the interaction between personality traits and situations have not been systematized, and empirical study findings have not been consistent [27]. 
2.3.2. Relationship between Team Context and Exploitation and Exploration, and the Interaction between Personality Traits and Team Context

(1) Support from team members and the team leader

"Support", in the social context [1], means a contextual element that encourages members to give help and support one another. Support can be established when management makes efforts to help and guide its members, and such support plays an important role in exploitation and exploration. In the work environment, supportive behaviors from colleagues and the boss enable an individual to show further creativity [28].

The study focuses on support designed for exploration, which is difficult to achieve, and regards how much support team members and leaders provide to encourage exploration. Given that exploration is much more difficult and likely to fail than exploitation, when an individual makes an attempt, support from the team leader and team members is more necessary than anything else. When support is provided for exploration, members likely actively engage in exploration activities. A context that demands and supports innovation serves as a motivation for exploration.

How favorable the boss and colleagues are toward exploration activities, and whether they can discuss them together, is also important. Support from colleagues has a positive effect on various outcome variables, such as employees' job attitude or performance [29]. A team should perform as members of an institution, called an organization, and be bound by institutional limitations. Therefore, the level of exploration activities varies depending on the extent to which the team demands and supports exploration activities.

Hypothesis 3 (H3). Support from the team leader for exploration is positively related to individual exploration.

Hypothesis 4 (H4). Support from team members for exploration is positively related to individual exploration.

Those with high-level openness to experiences can perform better in a job or context that requires creativity and innovation (e.g., [27]). Therefore, establishing a team context that supports innovative exploration activities is important. As those with high-level openness to experiences want to expand their experiences, including in their work environment, an environment that requires innovation is important for them [23]. As the environment requires innovation and values exploration activities, such as innovation, a context that supports such activities is important.

One example of support from the boss is that, because people with high-level openness to experiences have a strong tendency for learning, their efforts can create a synergetic effect with support from the boss. Given that they likely feel interested in a challenging task and actively commit themselves to the task if they are willing to learn, support from the boss may help increase their exploration activities [30]. The boss acts as a facilitator when members perform exploration activities. When they perceive support from the boss positively, their motivation for exploration increases.

Hypothesis $\mathbf{5}$ (H5). Support from the team leader positively moderates the relationship between openness to experiences and exploration.

Hypothesis 6 (H6). Support from team members positively moderates the relationship between openness to experiences and exploration.

\section{(2) Knowledge sharing}

"Stretch", in the performance management context, suggested by Gibson and Birkinshaw [1], refers to a contextual element that encourages members to voluntarily work for an ambitious goal. Establishing a shared vision, setting up a shared identity, and sharing knowledge all contribute to forming a stretch; thus, perceptions about how well knowl- 
edge is shared in the team may have an effect on individual exploitation and exploration activities.

Exploitation and exploration are certain types of learning [26]. Both can be performed better when knowledge serves as the basis. Thus, establishing a context conducive to learning can further improve exploitation and exploration levels. Specifically, exploration activities can occur often when learning is elicited to the maximum, and knowledge sharing can facilitate learning. To well produce and exploit knowledge, not only individual competencies but also competencies to combine and integrate interactions among employees are important [31].

With knowledge sharing, team members share ideas and information about their tasks with others [32], and knowledge sharing leads to creative ideas and forms strong social capital with other people. Furthermore, speaking about implicit knowledge produces cognitive effects, such as deep understanding and improved knowledge. That is, benefits from cognitive and social exchanges, inherent to knowledge sharing, facilitates creative ideas [33].

New knowledge is created from the combination and exchange of knowledge [34]. To combine knowledge, members with different knowledge should exchange knowledge. Knowledge sharing helps create new knowledge by sharing and disseminating the knowledge of small groups and individuals scattered across the organization [35]. Task-related knowledge in members is important to produce new and useful ideas [36], and knowledge sharing is greatly needed to ensure not only explicit knowledge but also implicit knowledge, as well as knowledge depth and diversity.

Hypothesis 7 (H7). Knowledge sharing is positively related to individual exploitation and exploration.

Knowledge sharing helps (enables) the relationship between openness to experiences and exploration and reinforces the strength of that relationship. In the relationship between conscientiousness and exploitation, knowledge sharing works as a strong situation and weakens the strength of the relationship.

Creating new knowledge from knowledge sharing is necessary to help those with high-level openness to experiences conduct exploration activities well. Given that exploration is difficult to achieve and requires various ideas, the team's knowledge sharing is indispensable for exploration. Those with high-level openness to experiences, who have considerable curiosity, an open attitude, and a strong desire for diversity, knowledge sharing with other team members, reinforce exploration activities.

From the above Hypothesis 2, conscientious people are expected to pursue more exploitation activities than exploration activities. When many knowledge combinations and exchanges through knowledge sharing exist, much exploitation can be achieved, due to the effect of knowledge sharing where conscientiousness is less activated. Knowledge sharing facilitates the exploitation of knowledge resources and contributes to exploitation, which utilizes and improves existing knowledge. It also works as a strong situation in the relationship between conscientiousness and exploitation.

Hypothesis 8 (H8). Knowledge sharing negatively moderates the relationship between conscientiousness and exploitation.

Hypothesis 9 (H9). Knowledge sharing positively moderates the relationship between openness to experiences and exploration.

\section{Method}

\subsection{Data Collection}

To test the hypotheses, a questionnaire survey was conducted in a cosmetics firm and a chemical firm in Korea. A total of 174 employees responded to the questionnaire: 68 from the cosmetics firm, and 106 from the chemical firm. Before the questionnaire survey 
was conducted, in-depth interviews were performed to refine the questionnaire items on individual exploitation and exploration. The interviews were conducted on a research and development (R\&D) team and a product development team, in the research teams of both firms. The questionnaire copies were also collected from the researchers in these teams.

The respondents from the research center of the cosmetics firm were mostly researchers in the product development team, with 3-7 years of service. The respondents from the research center of the chemical firm included those from a basic material lab, a battery lab, information electronics/material/central labs, and a technology planning team, with senior or principal researcher titles.

The authors intended to select organizations whose members can perform both of exploitation and exploration activities as the sample. Although the R\&D team members in the surveyed firms showed more exploitation activities than exploration ones, they also performed exploration activities. In general, R\&D teams solve problems by using individuals' creative ideas and produce performance output in individual R\&D; thus, both exploitation and exploration are necessary.

The first interview was conducted at the two firms, and the second in-depth interview was conducted on researchers at the cosmetics firm. The first interview lasted for one hour each, with three team leaders (general managers) from the cosmetics firm and two researchers (deputy general managers) from the chemical firm for questions and answers on their team context. The authors attempted to determine what exactly were the exploitation and exploration activities in their actual work, how they were categorized, and whether an individual handled both together. The second interview lasted for one hour each, with four researchers (assistant managers or managers), who were responsible for implementing the actual work. The authors asked the firm to select two of them who pursued exploitation well and two others who pursued exploration well for the interview. By pilot testing preliminary questionnaire items about exploitation and exploration, the authors refined the items. A survey with the preliminary questionnaire items showed that the average level of exploration for researchers good at exploration was higher than that for researchers good at exploitation, confirming a difference between the two groups in average exploitation and exploration. Final questionnaire items were developed using feedback on the preliminary questionnaire items from the interviewees.

\subsection{Operational Definition and Measurement of the Variables}

\subsubsection{Independent Variables}

Openness to experience and conscientiousness of the five personality traits were based on questionnaire items from Goldberg [37], and some items were revised in reference to the NEO personality inventory revised [38]. Openness to experiences consisted of 10 items, including "I often come up with great ideas"; conscientiousness also comprised 10 items, including "I try to faithfully carry out all tasks entrusted to me". Cronbach's alpha for the openness scale was 0.9 , and 0.87 for Conscientiousness.

\subsubsection{Dependent Variables}

In this study, exploitation was defined as "improving existing knowledge and ideas and extracting value by an individual relying on previous knowledge" and exploration as "looking for a new idea on the basis of new knowledge, which has not been used". Each questionnaire item was revised in reference to the interviewees' feedback based on suggestions from Kostopoulos and Bozionelos [39] and Mom et al. [16]. Cronbach's alpha for the complete scale for exploitation was 0.92 and 0.9 for exploration. All the questionnaire items are in the Appendix A.

\subsubsection{Moderating Variables}

Support from team members and the team leader was defined as support for exploration and revised specifically for exploration on the basis of the item "support for 
creativity" by Madjar et al. [40]. Cronbach's alpha for leader support scale was 0.95, and Cronbach's alpha for coworker (team member) support was 0.94 .

Knowledge sharing entails team members sharing task-related ideas and information with others [32]. Team members' individual perceptions about knowledge sharing were also measured in this study. Seven items developed by Srivastava et al. [32] were used for measurement, which included special knowledge and general information as sharable knowledge. Cronbach's alpha for the complete scale was 0.93.

\subsubsection{Control Variables}

An individual's age, sex, and years of service in his or her organization and team were used as the control variables, based on previous studies; these variables may play important roles in individual exploitation and exploration.

\section{Results}

\subsection{Relationship among Openness to Experiences, Conscientiousness, and Exploitation and} Exploration

Table 1 shows the correlations between the variables used in this study. Openness and conscientiousness showed a high correlation with exploitation and exploration. Variables with a high correlation of 0.5 or higher are leader support and coworker support, exploration and leader support, and exploration and coworker support.

Table 1. Correlation.

\begin{tabular}{|c|c|c|c|c|c|c|c|c|c|c|c|c|c|}
\hline & Mean & SD & 1 & 2 & 3 & 4 & 5 & 6 & 7 & 8 & 9 & 10 & 11 \\
\hline 1. Gender & 0.52 & 0.50 & & & & & & & & & & & \\
\hline 2. Company & 0.39 & 0.49 & $-0.16^{*}$ & & & & & & & & & & \\
\hline 3. Age & 35.74 & 5.62 & $0.16^{*}$ & $0.22 * *$ & & & & & & & & & \\
\hline 4. Oyears & 7.58 & 5.13 & -0.01 & $0.18 *$ & $0.78^{* *}$ & & & & & & & & \\
\hline 5. Tyears & 3.32 & 3.12 & 0.11 & -0.10 & $0.30^{* *}$ & $0.42 * *$ & & & & & & & \\
\hline 6. Openness & 4.85 & 0.91 & $0.36 * *$ & 0.09 & 0.13 & -0.05 & -0.06 & & & & & & \\
\hline 7. Conscientiousness & 5.26 & 0.75 & 0.15 & 0.08 & 0.12 & 0.03 & 0.02 & $0.44^{* *}$ & & & & & \\
\hline 8. Exploitation & 4.47 & 1.53 & 0.06 & $0.29 * *$ & $0.16^{*}$ & $0.16 *$ & $0.19 *$ & $0.19 *$ & $0.29 * *$ & & & & \\
\hline 9. Exploration & 4.43 & 1.23 & 0.15 & $0.30^{* *}$ & $0.21 * *$ & 0.12 & 0.15 * & 0.48 ** & $0.34^{* *}$ & $0.66^{* *}$ & & & \\
\hline 10. LS & 5.20 & 1.20 & $0.15 *$ & $0.23 * *$ & 0.07 & 0.01 & 0.09 & $0.48^{* *}$ & $0.39 * *$ & $0.45^{* *}$ & $0.61 * *$ & & \\
\hline 11. CS & 5.46 & 1.05 & 0.09 & $0.22 * *$ & $0.15 *$ & 0.09 & 0.11 & $0.42 * *$ & $0.35 * *$ & $0.39 * *$ & $0.53 * *$ & $0.78^{* *}$ & \\
\hline 12. KS & 5.44 & 0.90 & 0.01 & 0.08 & 0.07 & 0.02 & 0.09 & $0.29 * *$ & $0.29 * *$ & $0.31 * *$ & $0.43^{* *}$ & $0.53 * *$ & $0.63^{* *}$ \\
\hline
\end{tabular}

$n=174 .{ }^{*} p<0.05 ;{ }^{* *} p<0.01$. Oyears: organization working years; Tyears: team working years; LS: leader support CS: coworker support; KS: knowledge sharing.

To test the hypotheses, the authors conducted a hierarchical regression analysis (Tables 2-4). It indicated that conscientiousness had a statistically significantly positive effect on exploitation $(\beta=0.22, p<0.01)$, but openness to experiences did not have a significant effect on exploitation. By contrast, openness to experiences had a significantly positive effect on exploration $(\beta=0.41, p<0.001)$. As a result, $\mathrm{H} 1$ and $\mathrm{H} 2$ were supported.

\subsection{Effect of the Context Variables and the Moderating Effect at the Two Firms}

As displayed in Model 3, of Tables 2-4, all contextual variables had statistically significant effects on exploitation and exploration. As seen in Tables 2 and 3, leader and coworker support had significant effects on exploration; thus, $\mathrm{H} 3$ and $\mathrm{H} 4$ were supported. However, the moderating effect on exploration was not significant.

As seen in Table 4 , the $t$-test revealed that knowledge sharing had a positive effect on exploitation $(\beta=0.21, p<0.01)$ and exploration $(\beta=0.27, p<0.001)$. Thus, H7 was supported. 
Table 2. Regression analysis results: personalities, leader support (LS), and interactions predicting dependent variables (company A + company B).

\begin{tabular}{|c|c|c|c|c|c|c|c|c|}
\hline \multirow{3}{*}{ Variables } & \multicolumn{4}{|c|}{ Exploitation } & \multicolumn{4}{|c|}{ Exploration } \\
\hline & Model 1 & Model 2 & Model 3 & Model 4 & Model 1 & Model 2 & Model 3 & Model 4 \\
\hline & $\beta$ & $\beta$ & $\beta$ & $\beta$ & $\beta$ & $\beta$ & $\beta$ & $\beta$ \\
\hline Gender & 0.08 & 0.03 & 0.02 & 0.03 & $0.15 *$ & 0.00 & -0.02 & -0.02 \\
\hline Company & $0.33^{* * *}$ & $0.29 * * *$ & $0.21 * *$ & $0.21 * *$ & $0.33^{* * *}$ & $0.27 * * *$ & $0.17^{* *}$ & $0.17 * *$ \\
\hline Age & 0.02 & -0.04 & -0.01 & 0.01 & 0.17 & 0.04 & 0.09 & 0.10 \\
\hline Oyears & -0.01 & 0.05 & 0.05 & 0.04 & -0.15 & -0.02 & -0.02 & -0.02 \\
\hline Tyears & $0.21 *$ & $0.21^{* *}$ & 0.15 * & 0.14 & $0.18 *$ & $0.20^{* *}$ & $0.13 *$ & $0.13 *$ \\
\hline Openness (O) & & 0.08 & -0.06 & -0.08 & & $0.41^{* * *}$ & $0.25^{* * *}$ & $0.26^{* * *}$ \\
\hline Conscientiousness (C) & & $0.22 * *$ & 0.15 & $0.16^{*}$ & & 0.12 & 0.03 & 0.04 \\
\hline LS & & & $0.35 * * *$ & $0.34^{* * *}$ & & & $0.43^{* * *}$ & $0.46^{* * *}$ \\
\hline $\mathrm{O} \times \mathrm{LS}$ & & & & 0.13 & & & & 0.15 \\
\hline$C \times L S$ & & & & $-0.25^{*}$ & & & & -0.12 \\
\hline $\mathrm{F}$ & $5.563^{* * *}$ & $6.145^{* * *}$ & $8.377^{* * *}$ & $7.613^{* * *}$ & $6.675^{* * *}$ & $12.955^{* * *}$ & $18.757^{* * *}$ & $15.333^{* * *}$ \\
\hline $\mathrm{R} 2$ & 0.144 & 0.208 & 0.291 & 0.321 & 0.167 & 0.356 & 0.479 & 0.488 \\
\hline$\Delta \mathrm{R} 2$ & & $0.064^{* *}$ & $0.084^{* * *}$ & $0.030 *$ & & $0.189 * * *$ & $0.123^{* * *}$ & 0.008 \\
\hline
\end{tabular}

$n=174 .{ }^{*} p<0.05 ;{ }^{* *} p<0.01 ;{ }^{* * *} p<0.001$. LS: leader support.

Table 3. Regression analysis results: personalities, coworker support (CS), and interactions predicting dependent variables (company A + company B).

\begin{tabular}{|c|c|c|c|c|c|c|c|c|}
\hline \multirow{3}{*}{ Variables } & \multicolumn{4}{|c|}{ Exploitation } & \multicolumn{4}{|c|}{ Exploration } \\
\hline & Model 1 & Model 2 & Model 3 & Model 4 & Model 1 & Model 2 & Model 3 & Model 4 \\
\hline & $\beta$ & $\beta$ & $\beta$ & $\beta$ & $\beta$ & $\beta$ & $\beta$ & $\beta$ \\
\hline Gender & 0.08 & 0.03 & 0.04 & 0.04 & $0.15 *$ & 0.00 & 0.01 & 0.01 \\
\hline Company & $0.33^{* * *}$ & $0.29 * * *$ & $0.25 * * *$ & $0.24 * *$ & $0.33^{* * *}$ & $0.27 * * *$ & $0.21 * *$ & $0.21 * *$ \\
\hline Age & 0.02 & -0.04 & -0.04 & -0.05 & 0.17 & 0.04 & 0.05 & 0.05 \\
\hline Oyears & -0.01 & 0.05 & 0.04 & 0.04 & -0.15 & -0.02 & -0.03 & -0.03 \\
\hline Tyears & $0.21 *$ & $0.21^{* *}$ & 0.17 * & $0.17^{*}$ & 0.18 * & $0.20 * *$ & $0.15^{*}$ & $0.15^{*}$ \\
\hline Openness (O) & & 0.08 & -0.01 & -0.03 & & $0.41^{* * *}$ & $0.30 * * *$ & $0.30 * * *$ \\
\hline Conscientiousness (C) & & $0.22 * *$ & $0.17^{*}$ & $0.18 *$ & & 0.12 & 0.07 & 0.06 \\
\hline CS & & & $0.26 * * *$ & 0.24 ** & & & $0.31 * * *$ & $0.31 * * *$ \\
\hline $\mathrm{O} \times \mathrm{CS}$ & & & & 0.10 & & & & 0.06 \\
\hline $\mathrm{C} \times \mathrm{CS}$ & & & & $-0.27^{* *}$ & & & & -0.10 \\
\hline $\mathrm{F}$ & $5.563 * * *$ & $6.145^{* * *}$ & $7.120 * * *$ & $6.990 * * *$ & $6.675^{* * *}$ & $12.955^{* * *}$ & 15.161 & 12.245 \\
\hline $\mathrm{R} 2$ & 0.144 & 0.208 & 0.259 & 0.303 & 0.167 & 0.356 & 0.427 & 0.432 \\
\hline$\Delta \mathrm{R} 2$ & & $0.064^{* *}$ & $0.051 * *$ & $0.044 * *$ & & $0.189^{* * *}$ & $0.071 * * *$ & 0.005 \\
\hline
\end{tabular}

$n=174 .{ }^{*} p<0.05 ;{ }^{* *} p<0.01 ;{ }^{* * *} p<0.001$. CS: coworker support.

Table 4. Regression analysis results: personalities, knowledge sharing (KS), and interactions predicting dependent variables (company A + company B).

\begin{tabular}{|c|c|c|c|c|c|c|c|c|}
\hline \multirow{3}{*}{ Variables } & \multicolumn{4}{|c|}{ Exploitation } & \multicolumn{4}{|c|}{ Exploration } \\
\hline & Model 1 & Model 2 & Model 3 & Model 4 & Model 1 & Model 2 & Model 3 & Model 4 \\
\hline & $\beta$ & $\beta$ & $\beta$ & $\beta$ & $\beta$ & $\beta$ & $\beta$ & $\beta$ \\
\hline Gender & 0.08 & 0.03 & 0.06 & 0.06 & 0.15 * & 0.00 & 0.03 & 0.03 \\
\hline Company & $0.33^{* * *}$ & $0.29 * * *$ & $0.29^{* * *}$ & $0.26^{* * *}$ & $0.33^{* * *}$ & $0.27^{* * *}$ & $0.25^{* * *}$ & $0.25 * * *$ \\
\hline Age & 0.02 & -0.04 & -0.05 & -0.04 & 0.17 & 0.04 & 0.03 & 0.03 \\
\hline Oyears & -0.01 & 0.05 & 0.06 & 0.07 & -0.15 & -0.02 & 0.00 & 0.02 \\
\hline Tyears & $0.21 *$ & $0.21 * *$ & 0.18 * & $0.16^{*}$ & 0.18 * & $0.20 * *$ & $0.16^{*}$ & 0.15 * \\
\hline Openness (O) & & 0.08 & 0.03 & 0.04 & & $0.41^{* * *}$ & $0.35^{* * *}$ & $0.37 * * *$ \\
\hline Conscientiousness (C) & & $0.22 * *$ & $0.18 *$ & $0.17^{*}$ & & 0.12 & 0.07 & 0.06 \\
\hline KS & & & $0.21^{* *}$ & $0.22 * *$ & & & $0.27^{* * *}$ & $0.28^{* * *}$ \\
\hline $\mathrm{O} \times \mathrm{KS}$ & & & & 0.10 & & & & 0.11 \\
\hline $\mathrm{C} \times \mathrm{KS}$ & & & & $-0.19 *$ & & & & -0.09 \\
\hline $\mathrm{F}$ & $5.563 * * *$ & $6.145^{* * *}$ & $6.648^{* * *}$ & $6.011 * * *$ & $6.675^{* * *}$ & $12.955^{* * *}$ & $14.804^{* * *}$ & $12.198 * * *$ \\
\hline $\mathrm{R} 2$ & 0.144 & 0.208 & 0.246 & 0.272 & 0.167 & 0.356 & 0.421 & 0.431 \\
\hline$\Delta \mathrm{R} 2$ & & $0.064^{* *}$ & $0.038^{* *}$ & 0.026 & & $0.189^{* * *}$ & $0.065^{* * *}$ & 0.010 \\
\hline
\end{tabular}


An analysis of the two firms combined showed that the moderating effect was only tested in the relationship between conscientiousness and exploitation in both firms. The interaction term was only significant in the relationship between conscientiousness and exploitation. $\mathrm{H} 8$ about knowledge sharing predicted the moderating effect in the relationship between conscientiousness and exploitation, and it was supported.

To test whether knowledge sharing moderated the effect of conscientiousness on exploitation, the authors conducted a hierarchical regression analysis. When the dependent variable was exploitation, Model 4, which added the interaction term and was also found to statistically fit $(\mathrm{F}=6.011, p<0.001)$. The $t$-test showed that the interaction term between openness to experiences and knowledge sharing was insignificant, but the interaction term between conscientiousness and knowledge sharing was significantly negative $(\beta=-0.19$, $p<0.05)$. That is, knowledge sharing in the relationship between conscientiousness and exploitation was found to have a negative moderating role and can be considered to weaken the strength of the relationship between conscientiousness and exploitation.

With low-level knowledge sharing, the effect of conscientiousness on exploitation was found to be significantly positive, whereas that of conscientiousness on exploitation was insignificant when the level of knowledge sharing was high (Figure 2). That is, exploitation was greatly increased by conscientiousness when the level of knowledge sharing was low, whereas exploitation was almost unchanged by conscientiousness when the level of knowledge sharing was high.

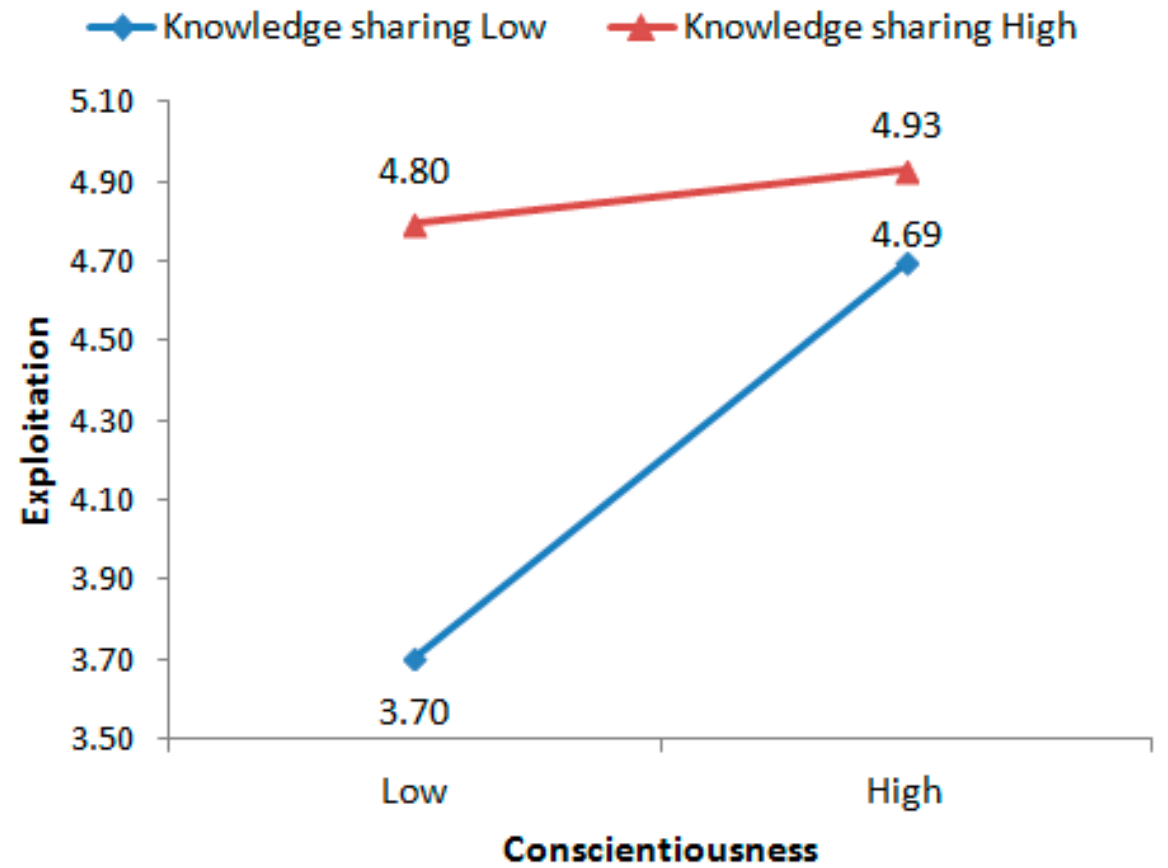

Figure 2. Moderating effects of knowledge sharing on the relationship between conscientiousness and exploitation (company A + company B).

\subsection{Effect of the Context Variables and the Moderating Effect at Firm B}

A statistical analysis of the two firms combined confirmed the importance of contextual variables, as each contextual variable had a positive effect on exploration; but no moderating effect that interacted in the relationship between openness to experiences and exploration was found. When analyzed individually, Firm A had no moderating effect, whereas Firm B showed the moderating effect of support from the team leader on exploration.

The reason Firm A did not show a moderating effect was that producing a significant moderating effect was difficult, as Firm A already had a fairly high level of openness to experiences and exploration, variance around the mean was low, and the difference between individuals in exploration and openness to experiences was not that large. The mean of exploration was 4.89 and standard deviation was 0.88 at Firm A. 
By contrast, Firm B, which is a chemical firm, had a low mean for exploration but a high variance level, which resulted in clear individual differences and led to a significant moderating effect. The mean of exploration was 4.11, and the standard deviation was 1.59 at Firm B. Hence, the hypotheses about the effect of the context variables were tested, whereas those about the moderating effect were partially tested.

For the effect of the context variables on exploration and the moderating effect, all the context variables had a significantly positive effect on exploration at Firm B, as seen in Tables 5-7. For the moderating effect, support from the team leader showed a positive moderating effect in the relationship between openness to experiences and exploration.

Table 5. Regression analysis results: personalities, leader support, and interactions predicting dependent variables (company B).

\begin{tabular}{|c|c|c|c|c|c|c|c|c|}
\hline \multirow{3}{*}{ Variables } & \multicolumn{4}{|c|}{ Exploitation } & \multicolumn{4}{|c|}{ Exploration } \\
\hline & Model 1 & Model 2 & Model 3 & Model 4 & Model 1 & Model 2 & Model 3 & Model 4 \\
\hline & $\beta$ & $\beta$ & $\beta$ & $\beta$ & $\beta$ & $\beta$ & $\beta$ & $\beta$ \\
\hline Gender & $0.21 *$ & 0.11 & 0.10 & 0.10 & 0.17 & -0.08 & -0.09 & -0.11 \\
\hline Age & 0.03 & -0.02 & 0.03 & 0.05 & 0.13 & 0.01 & 0.07 & 0.10 \\
\hline Oyears & 0.07 & 0.09 & 0.07 & 0.07 & -0.13 & -0.04 & -0.07 & -0.07 \\
\hline Tyears & $0.23 *$ & $0.23 *$ & 0.17 & 0.13 & $0.24 *$ & $0.26 *$ & $0.18 *$ & $0.18 *$ \\
\hline Openness (O) & & 0.12 & -0.06 & -0.09 & & $0.51^{* * *}$ & $0.30 * *$ & $0.34^{* *}$ \\
\hline Conscientiousness (C) & & 0.19 & 0.12 & 0.10 & & 0.13 & 0.05 & 0.04 \\
\hline LS & & & $0.40 * * *$ & $0.41^{* * *}$ & & & $0.45^{* * *}$ & $0.52 * * *$ \\
\hline $\mathrm{O} \times \mathrm{LS}$ & & & & 0.24 & & & & $0.30^{*}$ \\
\hline $\mathrm{C} \times \mathrm{LS}$ & & & & $-0.38^{* *}$ & & & & -0.21 \\
\hline $\mathrm{F}$ & $3.521 *$ & $3.720 * *$ & $5.600^{* * *}$ & $5.539 * * *$ & $2.696^{*}$ & $8.943^{* * *}$ & $13.059 * * *$ & $11.031^{* * *}$ \\
\hline $\mathrm{R} 2$ & 0.123 & 0.186 & 0.288 & 0.344 & 0.097 & 0.354 & 0.485 & 0.511 \\
\hline$\Delta \mathrm{R} 2$ & & 0.062 * & $0.102 * * *$ & 0.056 * & & $0.256^{* * *}$ & $0.131^{* * *}$ & 0.026 \\
\hline
\end{tabular}

$n=174 .{ }^{*} p<0.05 ;{ }^{* *} p<0.01 ;{ }^{* * *} p<0.001$.

Table 6. Regression analysis results: personalities, coworker support, and interactions predicting dependent variables (company B).

\begin{tabular}{|c|c|c|c|c|c|c|c|c|}
\hline \multirow{3}{*}{ Variables } & \multicolumn{4}{|c|}{ Exploitation } & \multicolumn{4}{|c|}{ Exploration } \\
\hline & Model 1 & Model 2 & Model 3 & Model 4 & Model 1 & Model 2 & Model 3 & Model 4 \\
\hline & $\beta$ & $\beta$ & $\beta$ & $\beta$ & $\beta$ & $\beta$ & $\beta$ & $\beta$ \\
\hline Gender & $0.21 *$ & 0.11 & 0.11 & 0.08 & 0.17 & -0.08 & -0.09 & -0.11 \\
\hline Age & 0.03 & -0.02 & -0.03 & -0.04 & 0.13 & 0.01 & 0.00 & 0.02 \\
\hline Oyears & 0.07 & 0.09 & 0.09 & 0.07 & -0.13 & -0.04 & -0.05 & -0.06 \\
\hline Tyears & $0.23 *$ & $0.23 *$ & 0.19 & 0.18 & $0.24 *$ & $0.26 *$ & $0.21 *$ & $0.21 *$ \\
\hline Openness (O) & & 0.12 & 0.00 & 0.00 & & $0.51 * * *$ & $0.36 * *$ & $0.39 * * *$ \\
\hline Conscientiousness (C) & & 0.19 & 0.15 & 0.12 & & 0.13 & 0.08 & 0.06 \\
\hline $\mathrm{CS}$ & & & $0.28 *$ & $0.27^{*}$ & & & $0.35^{* * *}$ & $0.40^{* * *}$ \\
\hline $\mathrm{O} \times \mathrm{CS}$ & & & & 0.21 & & & & 0.21 \\
\hline $\mathrm{C} \times \mathrm{CS}$ & & & & $-0.40^{* *}$ & & & & -0.19 \\
\hline $\mathrm{F}$ & $3.521 *$ & $3.720 * *$ & $4.385^{* * *}$ & $5.075^{* * *}$ & $2.696^{*}$ & $8.943^{* * *}$ & $10.867^{* * *}$ & $8.998^{* * *}$ \\
\hline $\mathrm{R} 2$ & 0.123 & 0.186 & 0.240 & 0.325 & 0.097 & 0.354 & 0.440 & 0.460 \\
\hline$\Delta \mathrm{R} 2$ & & $0.062 *$ & $0.055^{*}$ & $0.084^{* *}$ & & $0.256^{* * *}$ & $0.086^{* * *}$ & 0.021 \\
\hline
\end{tabular}

$n=174 .{ }^{*} p<0.05 ;^{* *} p<0.01 ;{ }^{* * *} p<0.001$.

A hierarchical regression analysis was conducted to test whether support from the team leader moderated the effect of openness to experiences on exploration; it revealed that, when the dependent variable was exploration, support from the team leader had a significantly positive effect on exploration $(\beta=0.45, p<0.001)$. Model 4 , which added the interaction term, was found statistically fit $(\mathrm{F}=11.031, p<0.001)$. The interaction term between openness to experiences and support from the team leader was significant $(\beta=0.30, p<0.05)$. That is, support from the team leader was found to have a positive moderating role in the relationship between openness to experiences and exploration, and support from the team leader can be considered to increase the strength of the relationship 
between openness to experiences and exploration (Table 5, Figure 3). As seen in Figure 3, with high-level leader support, exploration is higher when openness is high $(M=5.28)$ than when it is low $(\mathrm{M}=4.18)$.

Table 7. Regression analysis results: personalities, knowledge sharing, and interactions predicting dependent variables (company B).

\begin{tabular}{|c|c|c|c|c|c|c|c|c|}
\hline \multirow{3}{*}{ Variables } & \multicolumn{4}{|c|}{ Exploitation } & \multicolumn{4}{|c|}{ Exploration } \\
\hline & Model 1 & Model 2 & Model 3 & Model 4 & Model 1 & Model 2 & Model 3 & Model 4 \\
\hline & $\beta$ & $\beta$ & $\beta$ & $\beta$ & $\beta$ & $\beta$ & $\beta$ & $\beta$ \\
\hline Gender & $0.21 *$ & 0.11 & 0.11 & 0.10 & 0.17 & -0.08 & -0.09 & -0.09 \\
\hline Age & 0.03 & -0.02 & -0.01 & 0.00 & 0.13 & 0.01 & 0.03 & 0.02 \\
\hline Oyears & 0.07 & 0.09 & 0.10 & 0.11 & -0.13 & -0.04 & -0.04 & -0.01 \\
\hline Tyears & $0.23^{*}$ & $0.23 *$ & 0.19 & 0.18 & $0.24^{*}$ & $0.26 *$ & $0.21 *$ & $0.21 *$ \\
\hline Openness (O) & & 0.12 & 0.07 & 0.12 & & $0.51 * * *$ & $0.44^{* * *}$ & $0.50 * * *$ \\
\hline Conscientiousness (C) & & 0.19 & 0.12 & 0.12 & & 0.13 & 0.05 & 0.03 \\
\hline $\mathrm{KS}$ & & & $0.25 *$ & 0.24 * & & & $0.31^{* * *}$ & $0.32^{* * *}$ \\
\hline $\mathrm{O} \times \mathrm{KS}$ & & & & $0.21 *$ & & & & 0.18 \\
\hline $\mathrm{C} \times \mathrm{KS}$ & & & & $-0.22 *$ & & & & -0.09 \\
\hline $\mathrm{F}$ & $3.521 *$ & $3.720 * *$ & $4.244^{* * *}$ & $4.160 * * *$ & 2.696 * & $8.943^{* * *}$ & $10.531^{* * *}$ & $8.794 * * *$ \\
\hline $\mathrm{R} 2$ & 0.123 & 0.186 & 0.234 & 0.283 & 0.097 & 0.354 & 0.432 & 0.454 \\
\hline$\Delta \mathrm{R} 2$ & & $0.062 *$ & $0.049 *$ & $0.048 *$ & & $0.256^{* * *}$ & $0.078^{* * *}$ & 0.023 \\
\hline
\end{tabular}

$n=174 .{ }^{*} p<0.05 ;{ }^{* *} p<0.01 ;{ }^{* *} p<0.001$.

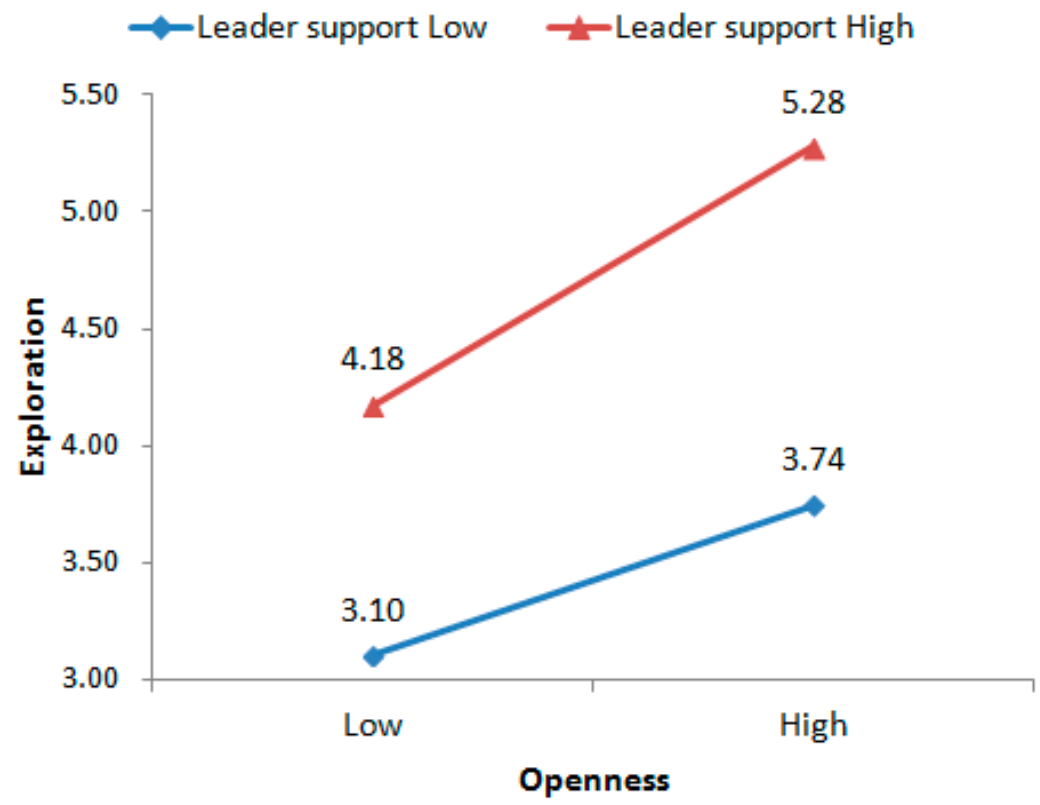

Figure 3. Moderating effects of leader support on the relationship between openness and exploration (company B).

Support from team members had a significantly positive relationship with exploration ( $\beta=0.35, p<0.001$ ), suggesting that high-level support from team members for exploration leads to high-level individual exploration (Table 6). However, support from team members did not show a significant moderating effect in the relationship between openness to experiences and exploration.

The effect of the context variables on exploitation and the moderating effect showed that each context variable at Firm B had a significantly positive effect on exploitation. In the relationship between conscientiousness and exploitation, knowledge sharing showed a negative moderating effect (Table 7). The t-test revealed that the interaction term between conscientiousness and knowledge sharing was significant $(\beta=-0.22, p<0.05)$. That is, knowledge sharing was found to have a negative moderating role in the relationship 
between conscientiousness and exploitation, and knowledge sharing weakened the strength of the relationship between conscientiousness and exploitation (Table 7, Figure 4).

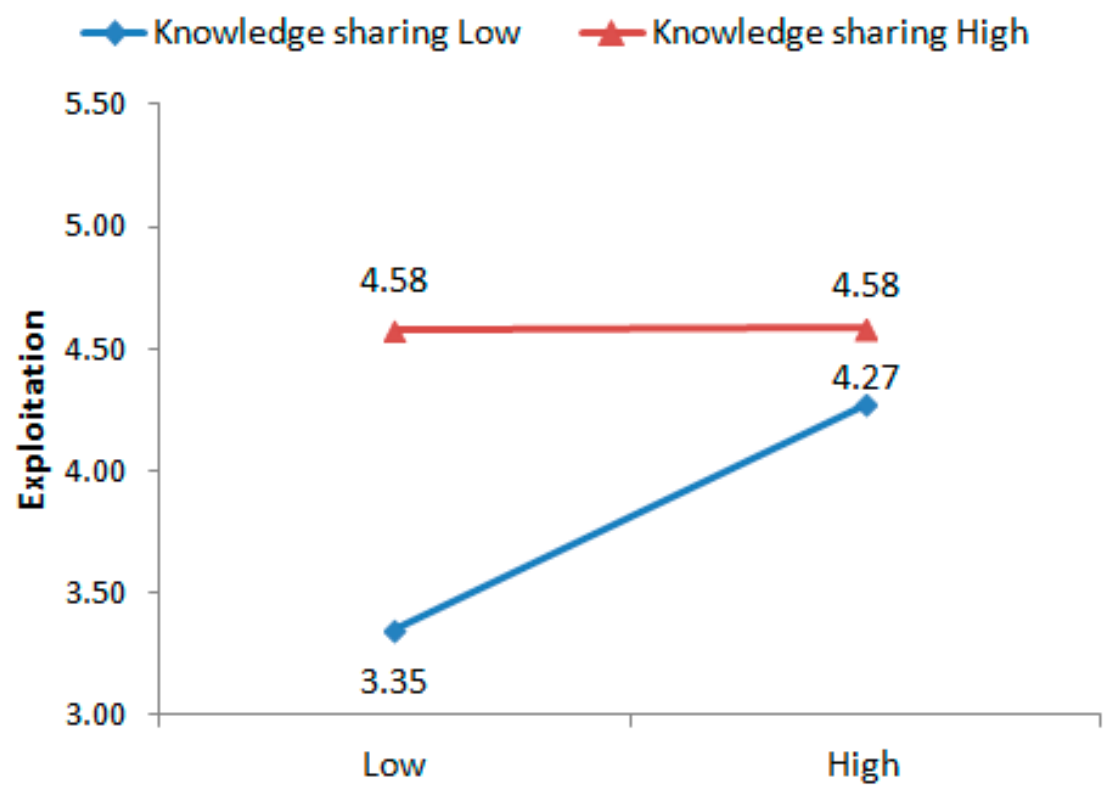

\section{Conscientiousness}

Figure 4. Moderating effects of knowledge sharing on the relationship between conscientiousness and exploitation (company B).

\section{Conclusions}

This study analyzed the effects that personality traits, team context, and the interaction between the two have on individual exploitation and exploration. The following summarizes the empirical results. First, personality traits were found to have an effect on individual exploitation and exploration activities. While those with high-level openness to experiences tended to pursue more exploration activities, those with high-level conscientiousness were found to engage in more exploitation activities.

Second, team context features, perceived by individuals, were also found to be important for individual exploitation and exploration activities. Support from the team leader and team members for exploration activities, as perceived by individuals, and knowledge sharing had positive effects on exploitation and exploration.

Third, the effect of the interaction between personality traits and team context on individual exploitation and exploration activities was also partially confirmed. An analysis of the two firms showed that each contextual variable, which were the moderating variables, mostly had a statistically significant effect on exploitation and exploration. However, the interaction term was significant in the relationship between conscientiousness and exploitation. Support from the team leader and team members, as perceived by individuals, and knowledge sharing weakened the strength of the positive relationship between conscientiousness and exploitation. Specifically, knowledge sharing, as a contextual variable, had such a large effect on exploitation, such that it limited the activation of personality traits. Consequently, the logic of the situation strength worked in the relationship between conscientiousness and exploitation, and these contexts became strong situations and weakened the strength of the positive relationship between conscientiousness and exploitation. In the relationship between openness to experiences and exploration at Firm B, support from the team leader enabled the relationship with exploration (an "enabling situation") and increased the strength of the relationship between openness to experiences and exploration.

As seen from the results of this study, personality traits and team context, as perceived by individuals, serve as positive factors for exploitation and exploration activities.

One of the cognitive psychology bases in behavioral strategies is to construct a reality through actors' subjective sensemaking of their environment [41]. This perspective served 
as the theoretical basis for this research. At the same time, this research contributes to such a perspective. Given that the different personality traits of members bring about different subjective interpretations of the tasks that they are facing, individual differences, including personality traits, cannot be ignored, as they relate to the type of creativity or exploitation and exploration activity; in addition, these personality traits, which have been overlooked so far, must be addressed [42].

In terms of business practices, the results of this study provide implications for selecting members for a team that requires exploitation or exploration (or establishing such an environment). While most teams need exploitation and exploration activities, if a team specializes more in exploitation or exploration activities, then establishing it with conscientious people, or those with high-level openness to experiences, is a good idea. Some teams are established for innovative projects, and they should continue to perform exploration activities, similar to future strategy teams, which require many people with high-level openness to experiences. In addition, teams that mainly deal with improving existing products and prioritize work efficiency may find those with high-level openness to experiences not that helpful; nevertheless, conscientious people can be useful for such teams. Moreover, the results suggest that constructing a certain team context and paying attention to the way team members perceive their team is important. When a context is formed, where the team leader and team members support one another's new ideas, and they can freely ask and share what they do not know well, such team members' exploration activities can be greatly increased.

A follow-up study is needed to explore further the personality traits and contextual variables that can interact for exploration activities, apart from the contextual variables suggested by this study. If other contextual variables that can interact with personality traits are investigated, then it will contribute to not only the theory of personality traits but also to that of contextual ambidexterity. Furthermore, the present study can be expanded to the team level, in addition to the individual level. A follow-up study may consider what personality traits are good at the team level and what can constitute exploitation and exploration activities at the team level.

Author Contributions: Conceptualization, M.P. and S.K.; methodology, M.P. and S.K.; software, M.P.; validation, M.P. and S.K.; formal analysis, M.P.; investigation, M.P. and S.K.; resources, S.K.; data curation, M.P. and S.K.; writing—original draft preparation, M.P.; writing—review and editing, S.K.; visualization, M.P.; supervision, S.K.; project administration, M.P. and S.K.; funding acquisition, S.K. All authors have read and agreed to the published version of the manuscript.

Funding: The authors thank Institute of Management Research (Seoul National University) for financial support.

Informed Consent Statement: Informed consent was obtained from all subjects involved in the study.

Data Availability Statement: The data that support the findings of this study are available from the corresponding author, Seongsu Kim, upon request.

Conflicts of Interest: The authors declare no conflict of interest.

\section{Appendix A}

$<$ Questionnaire $>$

Exploitation

1. I make some improvement of an existing product, material or concept.

2. I make some improvement of existing technology or know-how.

3. I come up with or develop some improved new ideas from existing products.

4. Sometimes I make improvements in efficiency of work performance.

5. I perform tasks, usually using existing knowledge and skills.

Exploration 
1. I experiment or propose a new and creative product, material, or concept that is different from the existing ones.

2. I come up with or develop new product ideas that have not been launched before.

3. I develop new products with new technologies.

4. I present creative new ideas.

5. I try things that others haven't tried before.

6. I tend to take a lot of risk.

7. I often use new knowledge and skills to perform the job.

Team leader's support for exploration [40]

1. My team leader(supervisor) encourages me to make time for exploration activities in addition to the task of the team's goals.

2. The team leader encourages team members to develop new ideas or skills.

3. The team leader positively considers the exploration activities of the team members in the personnel evaluation.

4. The team leader discusses with me my work-related ideas in order to improve them.

5. The team leader gives me useful feedback about my new ideas or exploration con cerning the workplace.

6. The team leader is always ready to support me if I introduce an unpopular/new idea or solution at work.

Team members' support for exploration [40]

1. My teammates(coworkers) other than my team leader(supervisor) are almost always supportive when I come up with a new idea about my job.

2. My teammates other than my supervisor give me useful feedback about my new ideas/exploration concerning the workplace.

3. My teammates other than my supervisor are always ready to support me if I introduce an unpopular/new idea or solution at work.

Knowledge sharing [32]

1. People in our team share their special knowledge and expertise with one another.

2. If someone in our team has some special knowledge about how to perform the team task, he or she is not likely to tell the other member about it (R).

3. There is virtually no exchange of information, knowledge, or sharing of skills among members (R).

4. More knowledgeable team members freely provide other members with hard-to-find knowledge or specialized skills.

5. Team members help others in developing ways or strategies to do their job.

6. Team members share lot of information with one another.

7. Team members make a lot of suggestions to others.

Personality traits $[37,38]$

1. I tend to know a lot of common sense and vocabulary.

2. I am very imaginative.

3. I often come up with great ideas.

4. I often fall into deep thoughts.

5. I am full of ideas.

6. I enjoy hearing new ideas.

7. I enjoy change.

8. I like to think about theories or abstract problems.

9. I have strong intellectual needs.

10. I have intellectual interests in various fields.

11. I am prepared for everything.

12. I tend to execute what I have planned.

13. I handle my work meticulously.

14. I often mess things up. 
15. There are times when I don't do what I need to do.

16. I complete tasks successfully.

17. I get things done efficiently.

18. I try to faithfully carry out all tasks entrusted to me.

19. I work hard to achieve my goals.

20. I seek the best in everything I do.

\section{References}

1. Gibson, C.B.; Birkinshaw, J. The antecedents, consequences, and mediating role of organizational ambidexterity. Acad. Manag. J. 2004, 47, 209-226.

2. Tushman, M.L.; O'Reilly, C.A. Ambidextrous organizations: Managing evolutionary and revolutionary change. Calif. Manag. Rev. 1996, 38, 8-30. [CrossRef]

3. Kang, S.C.; Snell, S.A. Intellectual capital architectures and ambidextrous learning: A framework for human resource management J. Manag. Stud. 2009, 46, 65-92. [CrossRef]

4. Mom, T.J.M.; Fourné, S.P.L.; Jansen, J.J.P. Managers' work experience, ambidexterity, and performance: The contingency role of the work context. Hum. Resour. Manag. 2015, 54, 133-153. [CrossRef]

5. Laureiro-Martinez, D.; Brusoni, S.; Zollo, M. The neuroscientific foundations of the exploration-exploitation dilemma. J. Neurosci. Psychol. Econ. 2010, 3, 95-115. [CrossRef]

6. Jasmand, C.; Blazevic, V.; Ruyter, K. Generating sales while providing service: A study of customer service representatives' ambidextrous behavior. J. Mark. 2012, 76, 20-37. [CrossRef]

7. Good, D.; Michel, E.J. Individual ambidexterity: Exploring and exploiting in dynamic contexts. J. Psychol. 2013, 147, 435-453. [CrossRef] [PubMed]

8. Barrick, M.R.; Mount, M.K.; Li, N. The theory of purposeful work behavior: The role of personality, higher-order goals, and job characteristics. Acad. Manag. Rev. 2013, 38, 132-153. [CrossRef]

9. Li, N.; Barrick, M.R.; Zimmerman, R.D.; Chiaburu, D.S. Retaining the productive employee: The role of personality. Acad. Manag. Ann. 2014, 8, 347-395. [CrossRef]

10. Cantarello, S.; Martini, A.; Nosella, A. A multi-level model for organizational ambidexterity in the search phase of the innovation process. Creat. Innov. Manag. 2012, 21, 28-48. [CrossRef]

11. Kauppila, O.P.; Tempelaar, M.P. The social-cognitive underpinnings of employees' ambidextrous behaviour and the supportive role of group managers' leadership. J. Manag. Stud. 2016, 53, 1019-1044. [CrossRef]

12. Raisch, S.; Birkinshaw, J.; Probst, G.; Tushman, M.L. Organizational ambidexterity: Balancing exploitation and exploration for sustained performance. Organ. Sci. 2009, 20, 685-695. [CrossRef]

13. Jansen, J.J.P.; van den Bosch, F.A.J.; Volberda, H.W. Exploratory innovation, exploitative innovation, and performance: Effects of organizational antecedents and environmental moderators. Manag. Sci. 2006, 52, 1661-1674. [CrossRef]

14. Rogan, M.; Mors, M.L. A network perspective on individual-level ambidexterity in organizations. Organ. Sci. 2014, 25, 1860-1877. [CrossRef]

15. Lee, S.; Meyer-Doyle, P. How performance incentives shape individual exploration and exploitation: Evidence from microdata Organ. Sci. 2017, 28, 19-38. [CrossRef]

16. Mom, T.J.M.; van den Bosch, F.A.J.; Volberda, H.W. Understanding variation in managers' ambidexterity: Investigating direct and interaction effects of formal structural and personal coordination mechanisms. Organ. Sci. 2009, 20, 812-828. [CrossRef]

17. Funder, D.C. Personality. Annu. Rev. Psychol. 2001, 52, 197-221. [CrossRef]

18. George, J.M.; Zhou, J. When openness to experience and conscientiousness are related to creative behavior: An interactional approach. J. Appl. Psychol. 2001, 86, 513-524. [CrossRef] [PubMed]

19. Costa, P.T.; McCrae, R.R. Revised NEO Personality Inventory (NEO PI-R) and NEO Five-Factor Inventory (NEO-FFI) Professional Manual; Psychological Assessment Resources: Odessa, FL, USA, 1992.

20. Zhao, H.; Seibert, S.E. The big five personality dimensions and entrepreneurial status: A meta-analytical review. J. Appl. Psychol. 2006, 91, 259-271. [CrossRef]

21. Dragoni, L.; Oh, I.; Vankatwyk, P.; Tesluk, P.E. Developing executive leaders: The relative contribution of cognitive ability, personality, and the accumulation of work experience in predicting strategic thinking competency. Pers. Psychol. 2011, 64, 829-864. [CrossRef]

22. McCrae, R.R.; John, O.P. An introduction to the five-factor model and its applications. J. Personal. 1992, 60, 175-215. [CrossRef] [PubMed]

23. McCrae, R.R.; Costa, P.T. Personality trait structure as a human universal. Am. Psychol. 1997, 52, 509-516. [CrossRef] [PubMed]

24. Barrick, M.R.; Mount, M.K. The Big Five personality dimensions: Implications for research and practice in human resource management. In Research in Personnel and Human Resource Management; Ferris, G., Ed.; JAI: Greenwich, CT, USA, 1995.

25. Keller, T.; Weibler, J. Behind managers' ambidexterity- Studying personality traits, leadership, and environmental conditions associated with exploration and exploitation. Schmalenbach Bus. Rev. 2014, 66, 309-333. [CrossRef]

26. March, J.G. Exploration and exploitation in organizational learning. Organ. Sci. 1991, 2, 71-87. [CrossRef] 
27. Judge, T.A.; Zapata, C.P. The person-situation debate revisited: Effect of situation strength and trait activation on the validity of the Big Five personality traits in predicting job performance. Acad. Manag. J. 2015, 58, 1149-1179. [CrossRef]

28. Oldham, G.R.; Cummings, A. Employee creativity: Personal and contextual factors at work. Acad. Manag. J. 1996, $39,607-634$.

29. Chiaburu, D.S.; Harrison, D.A. Do peers make the place? Conceptual synthesis and meta-analysis of coworker effects on perceptions, attitudes, OCBs, and performance. J. Appl. Psychol. 2008, 93, 1082-1103. [CrossRef]

30. Cho, Y. Goal orientation and job satisfaction: A mediating role of motivation and a moderating role of supervisor support. Korean J. Bus. Adm. 2017, 30, 835-855. (In Korean) [CrossRef]

31. Bae, J.; Park, O. Organizing ambidextrous HRM systems. J. Organ. Manag. 2010, 34, 31-68. (In Korean)

32. Srivastava, A.; Bartol, K.; Locke, E. Empowering leadership in management teams: Effects on knowledge sharing, efficacy, and performance. Acad. Manag. J. 2006, 49, 1239-1251. [CrossRef]

33. Rhee, Y.W.; Choi, J.N. Knowledge management behavior and individual creativity: Goal orientations as antecedents and in-group social status as moderating contingency. J. Organ. Behav. 2017, 38, 813-832. [CrossRef]

34. Huh, M. Social capital, knowledge creation, and innovation. Korean J. Manag. 2011, 19, 41-78. (In Korean)

35. Jang, S.H.; Roh, M.H.; An, S.C.; Son, S.Y. The influence of organizational identification on knowledge sharing behavior-focusing on the mediating effect of occupational self-efficacy. J. Hum. Resour. Manag. Res. 2014, 21, 217. (In Korean) [CrossRef]

36. Sung, S.Y.; Choi, J.N. Multiple dimensions of human resource development and organizational performance. J. Organ. Behav. 2014, 35, 851-870. [CrossRef]

37. Goldberg, L.R. The development of markers for the Big-Five factor structure. Psychol. Assess. 1992, 4, 26-42. [CrossRef]

38. Min, B.M.; Lee, K.I.; Jeong, J.C. The Korean Version of the NEO-PI-R; PSI Consulting: Seoul, Korea, 1997.

39. Kostopoulos, K.C.; Bozionelos, N. Team exploratory and exploitative learning: Psychological safety, task conflict, and team performance. Group Organ. Manag. 2011, 36, 385-415. [CrossRef]

40. Madjar, N.; Oldham, G.R.; Pratt, M.G. There's no place like home? The contributions of work and nonwork creativity support to employees' creative performance. Acad. Manag. J. 2002, 45, 757-767.

41. Weick, K.E. Sensemaking in Organizations; Sage: Thousand Oaks, CA, USA, 1995.

42. Madjar, N.; Greenberg, E.; Chen, Z. Factors for radical creativity, incremental creativity, and routine, noncreative performance. J. Appl. Psychol. 2011, 96, 730-743. [CrossRef] 